appreciated. Dr. John Ellis, the leading British medical educationalist, in a masterly paper entitled 'The Choice of Remedy', makes very clear the impossibility and the futility of trying to teach the medical student all that is known in all branches of medicine and the vital importance of using the undergraduate years to develop the mind of the doctor so that he may take full advantage of future advances in medical knowledge and so that he can easily assimilate postgraduate vocational training for whatever sphere of medicine he may choose as his life's work. Professor Richard Scott, the new Professor of General Practice in the University of Edinburgh, contributes a splendid paper on the work of the general practitioner in the community which should be read by all who consider this to be their metier.

Excellent sections on the importance of the basic sciences, psychology, psychiatry and social medicine in the preparation of the doctor for his work in the community are included and the final paper by Dr. Hobson from the World Health Organisation is outoutstanding. Dr. Hobson reviews the world-wide effect on medical education of the Flexner and Goodenough reports, the work in this field that has been done at Western Reserve University, and the contribution of the Association for the Study of Medical Education and of the World Health Organization itself.

\section{Textbook of Abnormal Psychology}

N. H. Pronko, Ph.D. Pp. xxii +446 , illustrated. Baltimore: Williams \& Wilkins. London: Baillière, Tindall \& Cox. I963. 68s.

Professor Pronko, who is Head of the Department of Psychology in the University of Wichita, prefaces his book by indicating that its "chief aim ... is to introduce the student to the facts and existing theories ordinarily subsumed under the category of abnormal psychology or psychopathology'.

The undergraduate will find that this volume is not a substitute for the several established introductory texts to psychiatry. Clinical descriptions of the various syndromes are brief and entirely inadequate for his needs, and on occasions are misleading. For instance, status epilepticus is briefly dismissed as follows: 'In advanced cases of arteriosclerosis in the senile, the degenerative changes in the blood vessels of the brain can erupt continually, bringing about status epilepticus in which one major attack follows another with little or no intermission. Eventually, the patient is killed off in one of the attacks of the chronic condition'. More space is given to some case histories than these would seem to warrant in terms of the contribution they make to the author's arguments. With regard to style, some readers will find that the rather chatty form of presentation soon becomes tedious. The term 'et cetera' is frequently employed-this term should have no place in any medical text book.

Professor Pronko does not confine himself to the more traditional and established doctrines of psychopathology but, incorporating less widely accepted theories, considers and evaluates conflicting viewpoints side-by-side. Whilst there is no attempt at systematically covering a field, this book's chief merit lies in the stimulus it will provide for discussion, particularly for postgraduate students.

\section{The Normal and Abnormal Unipolar Electro- cardiogram in Infants and Children}

Richard H. Wasserburger, M.D. Pp. ix + I 544, illustrated. Baltimore: Williams \& Wilkins. London: Baillière, Tindall \& Cox. 1963. $76 s$.

This book is sub-titled 'An analysis of the normal
QRS complex morphology and ventricular activation times' which indicates at once the limitations of the volume inasmuch as there is no discussion of the ST segment or $\mathrm{T}$ wave, or of arrhythmias. But even with these restrictions this study is a most valuable one starting as it does with a detailed analysis of the electrocardiograms of 1,150 normal infants and children. The data from this analysis are presented in graphic form and indicate the QRS configurations found in each lead at different ages together with the numerical values for the various deflections. This is a very good method of presentation and superior to the usual tedious tables of figures.

The second part of the book is concerned with the abnormal electrocardiogram and contains a thorough inquiry into the features of ventricular hypertrophy which is followed by discussions on some of the main congenital lesions of the heart and great vessels. In this section the $S T$ segment and $T$ waves are referred to.

Although it is not comprehensive this book will be indispensable to all those who are interested in pædiatric cardiology.

\section{Lectures on Experimental Gerontology}

F. Verzar, M.D. Pp. xvi + 128, illustrated. Springfield: Illinois. Charles C Thomas. I963. $\$ 5.75$.

Professor Verzar is known not only as a distinguished physiologist, but also as the founder of one of the first university departments in the world for the experimental study of ageing. In this book are printed a series of lectures which he gave in Basel, to the faculty of medicine, in 1961 .

Most of what is known of the effects of age on biological processes has hitherto been distributed among many different sciences, physiology, biochemistry, psychology, neurology, and others. In these lectures this scattered information is drawn together, organized and interpreted, much of it in the light of experiments conducted in the author's own laboratory.

The first few lectures are concerned with the methods of gerontological research, and show how complex is the process of ageing, and how it differs in various organisms. Methods of estimating the life span are discussed as well as the problems which arise from intercurrent illness and accidents. For example in nature the life span of some wild singing birds is about a year, but in captivity where accidents can be eliminated, it is about twenty years. Ageing may be considered as a process in which the organism gradually loses the power to adapt to its environment, and requires an increasing degree of protection for its survival. By exposing animals of different ages to cold, heat, and hypexia, Professor Verzar shows how this process can be studied in the laboratory.

The greater part of the book, however, is devoted to detailed studies of measurable age changes in collagen, muscle, nervous tissue, and sense organs. The final chapter looks to the future and suggests that at cellular level the ageing process may depend on changes in the DNA of the nucleus skin to those which can already be observed in collagen, since both have an apparently similar helical structure.

This book is translated from the German, but so well (the translator is the author's wife) that no-one would suspect it. It gives a most readable account of the physiology of ageing, and provides a most useful springboard for further advances in the future.

The increase in human life expectancy has already led to enormous social changes all over the world, and 